\title{
Innovative Method of Treating Sintered Metal Powders Surfaces with Optical Radiation Pulses, Using Gas-Discharge Lamp
}

\author{
IOAN VIRCA ${ }^{1}$, GHITA BARSAN ${ }^{1}$, CONSTANTIN BUNGAU ${ }^{2 *}$, DANUT MOSTEANU ${ }^{1}$, \\ SIMONA BUNGAU ${ }^{3}$, PAVEL OTRISAL ${ }^{4}$, FLORIN BANICA ${ }^{3}$, CORNEL HATIEGAN $^{5}$ \\ ${ }^{1}$ Nicolae Balcescu Land Forces Academy of Sibiu, 3-5 Revolutiei Str., 550170, Sibiu, Romania \\ ${ }^{2}$ Faculty of Managerial and Technological Engineering, University of Oradea, 1 Universitatii Str., 410087, Oradea, Romania \\ ${ }^{3}$ Faculty of Medicine and Pharmacy, University of Oradea, 29 Nicolae Jiga Str., 410028, Oradea, Romania. \\ ${ }^{4}$ Faculty of the Physical Culture, Palacky University Olomouc, 511/8 Krizkovskeho, 77111 Olomouc, Czech Republic \\ ${ }^{5}$ Eftimie Murgu University of Resita, 1-4 Traian Vuia Sq., 320085, Resita, Romania
}

\begin{abstract}
The research conducted in the present paper is part of a comprehensive study to innovate a method of surface treatment for some metallic powder materials with alternative energy sources to lasers and electron beams (i.e. with gas-discharge lamp (GDL)), typically used as sources of optical pumping for the lasers, having a solid active element. The radiant energy sources used for study are composed of a GDL and the high voltage power supply consists of a block of high-capacity capacitors. The materials were selected from the $\mathrm{Fe}-\mathrm{Cu}$ - $\mathrm{C}$ grade, with a carbon content between 0.5 to $0.72 \%$, and the measurements were made on microscopes with electron beam scanning. Configurational modifications of a surface layer of approximatively 30-35 $\mu$, characteristic for $\mathrm{Fe}-\mathrm{C}-\mathrm{Cu}$ alloys, containing nearly $0.7 \% C$ (pearlite, ferrite and cementite) are highlighted by the microscopic examinations. At the surface level, the energy flux created by the lamp in the visible spectrum, generates pressure, determining elongation of the surface layer pores, under optical action, resulting an effect comparable to plastic deformation by induration or compaction through mechanical actions. The results obtained highlight the potential of this class of materials to surface treatments and the options for the energy sources used.
\end{abstract}

Keywords: surface treatment, gas-discharge lamp (GDL), hardness, optical radiation pulses, metallic powders

\section{Introduction}

To satisfy the increasing demands of the more and more competitive market economy, engineering sciences are continuously searching for materials with low cost production as well as to implement modern technologies in the fields of machinery and equipment [1-3]. These are common objectives and practical approaches for scientists and specialists in the industrial field [4,5].

The treatments with optical radiation impulses are part of the category of non-conventional treatments, with concentrated energy, being extremely fast, over $10^{3} \mathrm{~K} / \mathrm{s}$. In the last 10-20 years, they have expanded, especially in the domains in which the processed materials allow structural changes in the surface layers (food industry, chemistry, medicine, ecology/environmental protection [6], textile industry [7], etc.).

These types of treatments produce strong local heating to the treated areas, with or without the melting of the surface of the treated material, while the energy intensity may exceed $10^{4} \mathrm{~W} / \mathrm{cm}^{2}$, and the effects consist in changing the superficial structure of the surface of the processed material $[8,9\}$.

Following a review of the literature, there have been identified several attempts to apply thermic treatment to compact metal materials using gas discharge lamps (GDLs) [10,11]. The authors performed heat treatments on metal surfaces with the energy of a GDL filled with xenon and found that the action of radiation flux significantly increases the surface microhardness in the processed area, compared to traditional methods of heat treatment. The results of the metallographic analysis showed that the hardened layers have austenitic-martensitic structure and present some structural differences compared 
to structures hardened by traditional methods. Also, the depth of the area of action of the radiation in pulse mode increased 2 times compared to the initial value [11]. In the same study, steel samples were subjected to hardening and a significant increase (from 23 to 62 HRC - Rockwell hardness tester classifications that are based on Rockwell scales) in hardness was obtained, with a maximum depth of the hardened area of $140 \mu \mathrm{m}$ [9]. Another study tried to alloy the surfaces of some concrete steel plates and the results showed that, in the working regime with an impulse, in the surface layer there was obtained both an alloy on the thickness of $45-50 \mu \mathrm{m}$ and the formation of a martensite/bainite structure [12].

The need to use GDL was dictated by the shortcomings found in similar hardening operations. For example, laser hardening of large surfaces requires a scan of the spot on the surface and inevitably leads to the remaining of uncovered or overloaded portions of the surface [13-15]. As a result, areas with low microhardness are formed on the surface [16-18]. The GDL was used to avoid these shortcomings, ensuring a uniform distribution of radiation over the entire processed surface. It also significantly shortens the duration of the technological process [10].

Since the hardening quality is mainly determined by the cooling conditions of the material $[19,20]$ in the temperature range between the austenite-martensite crossing points, and the preheating does not decrease the speed of heat penetration inside the material below the established limit, the result of hardening must be the same as in the case of preheating. On the other hand, preheating allows the energy required for hardening to be reduced by $30 \%$, which leads to a 10 -fold increase in the working resources of GDLs [10-12].

The research carried out in this paper aims to develop an innovative method of surface treatment with GDLs. The novelty of the present paper lies in the attempt to treat locally, with optical radiation impulses, areas on the surface of some metallic materials. Thus, the carried-out experimental investigations were oriented towards the category of materials obtained by sintering metallic powders. Due to their particular structure made of dust grains and pores, the metallic powder materials have a tendency to superficial heating, heat treatments and thermo hardening, enrichment with carbon and other alloying elements, etc., all of these being successfully implemented. This method of treatment with concentrated radiant energy sources applied to metallic powder materials is new and can become an important research direction, along with the laser and electron beams treatments.

\section{Materials and methods}

\subsection{Schematic diagram of heating the parts with electromagnetic radiation impulses}

The schematic diagram of a thermal treatment installation with electromagnetic radiation impulses, using the GDL as the radiation source is shown in Figure 1.

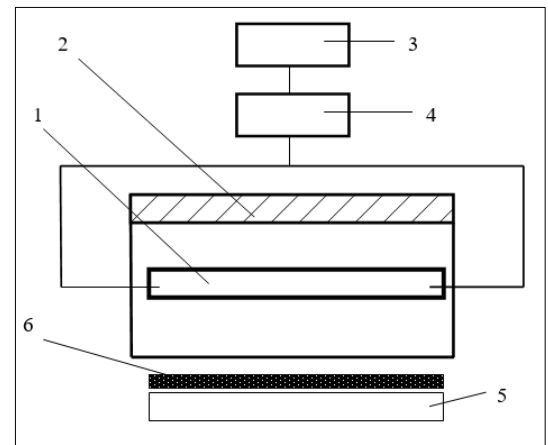

Figure 1. Schematic diagram of the surface

heat treatment with optical radiation impulses

(1) radiation source (gas discharge lamp);

(2) reflector; (3) supply source; (4) block of capacitors;

(5) metallic piece; (6) modified stratum 
The installation consists of the radiation source (1) (GDL) placed inside a reflector (2), making up a block. The lamp (1) is supplied from a capacitor block (3), which in turn is connected to a power supply source with a power frequency (4), equipped with a device for timing the electrical signal.

The piece subjected to the treatment (5) is located near the reflector slot (2), which has a parabolic shape, allowing a higher concentration of the radiant flux over the surface to be processed. The radiant flux spectrum is continuous in the area of visible waves $(380-780 \mathrm{~nm})$ and in short infrared $(\lambda \leq 1.1 \mu \mathrm{m})$; also, it is close to the radiant spectrum of the absolutely black body, at $9000 \mathrm{~K}$ (when an energy balance is reached) but in the GDL case, the maximum energy is reached at $\lambda_{\mathrm{m}}=0.5 \mu \mathrm{m}$ and in absolutely black body at $\lambda_{\mathrm{m}}=0.322 \mu \mathrm{m}$. The spectrum is similar to the sun spectrum, with a maximum intensity at the $\lambda_{\mathrm{m}}=0.5 \mu \mathrm{m}$ wavelength. When the duration of the impulse is decreased, the glow temperature of the plasma increases and can reach values of $10000-15000 \mathrm{~K}$, and the maximum spectral intensity moves to the area of the short-wave lengths $\left(\lambda_{\mathrm{m}}=0.35\right.$ to $\left.0.5 \mu \mathrm{m}\right)$.

The discharge takes place from a battery of high voltage capacitors at the sources operating in pulses. The pulse duration is of milliseconds $\left(\tau_{\mathrm{i}}=10^{-3} \div 10^{-4} \mathrm{~s}\right)$ and the radiation intensity depends on the voltage applied across the capacitor terminals and is between $100 \div 40000 \mathrm{~J}$ throughout a pulse, while the maximum power is between $10^{4}-10^{6} \mathrm{~W}$. The balloon lamp can be virtually executed in a variety of geometric shapes. Among the filling gases, xenon is the most commonly used because it has the highest coefficient of converting electric energy into radiant energy $(\eta=0.7)$. The STAS 10677-84 standard (regarding Surface hardening steels. Brands and quality technical conditions) [21] recommend steels that are suitable for surface heat treatments applied after a heat treatment for improving or normalizing and optionally followed by low tempering: OLC 35 CS; OLC 45 CS; OLC 55 CS; 40 Cr 10 CS; 40 BCr 10 CS; 33 MoCr $11 \mathrm{CS} ; 34 \mathrm{MoCrNi} 15 \mathrm{CS} ; 41 \mathrm{MoCr} 11 \mathrm{CS}$. In addition to the conditions relating to the material and heat treatment, it is necessary that the part is amenable to surface treatment procedure, that is, the areas to be hardened: be flat; be circular exterior or interior, with access to the heat source; have no rapid changes of section, not connected rays, small openings and sharp edges.

\subsection{Materials and experimental installation}

The sintered materials made by aggregation of metallic powders, which are the object of these investigations, were manufactured at Sinterom S.A. Cluj-Napoca. Thus, through the propensity of this economic agent to the enlargement of the area of investigation for discovering new manufacturing technologies and their assimilation in the production process, a number of materials sintered from the production flow were made available for research.

Following some preliminary analyses regarding the suitability of the sintered pieces to surface treatments, several types of pieces were provided for research, from which were chosen right lever type pieces (Figure 2) with a content of $0.7 \% \mathrm{C}, 7 \% \mathrm{Cu}$ and for the rest iron.

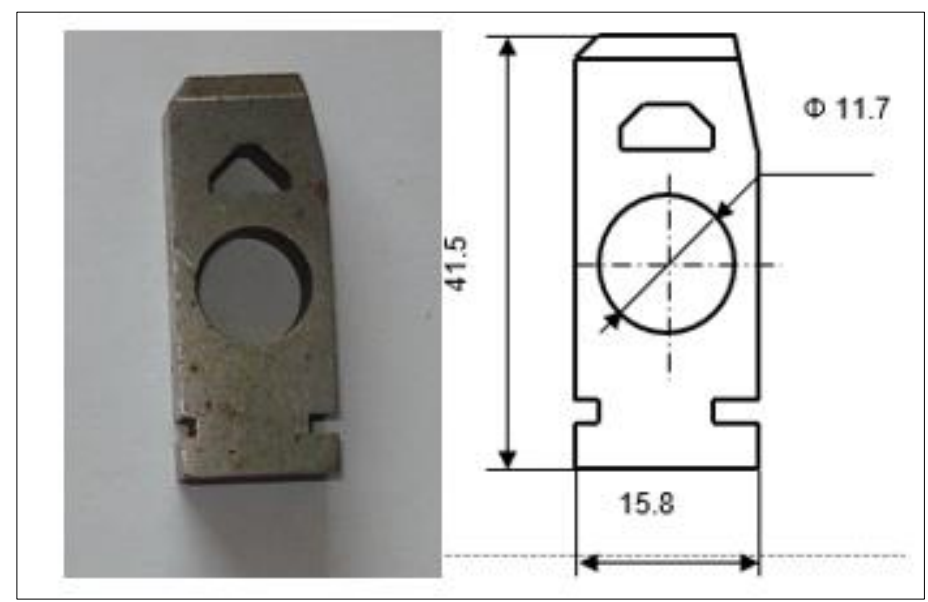

Figure 2. Right lever 
The installation is made up of the source of radiations, the GDL respectively, having a tubular shape (as it is shown in Figure 3), powered by a block of electrolytic capacitors with the $700 \mu \mathrm{F}$ capacity (Figure 4a).

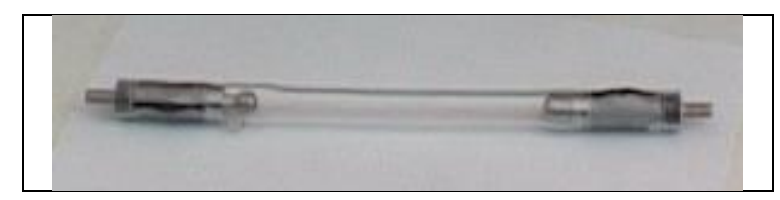

Figure 3. Gas-discharge lamp (GDL)

In Figure 4a, along with the block of capacitors, there are available one impulse lamp - IFP-800 (impulse ruby laser Nd:YAG pumping flash, Russian Federation). The lamps are disposed with the ends, which are also the external contacts in the power cables (Figures $4 \mathrm{~b}$ and $4 \mathrm{c}$ ), fixed in turn to the two holders. The block of capacitors is connected to the electric alternating current of $220 \mathrm{~V}$ and is provided with a control panel (Figure 4a) having buttons for uploading, adjusting and downloading the capacitors in order to achieve the operating voltage. Also, the front of the block is provided with a display screen for viewing the operating voltage (Figure $4 \mathrm{a}$ ), with a scale between $0-3 \mathrm{kV}$.

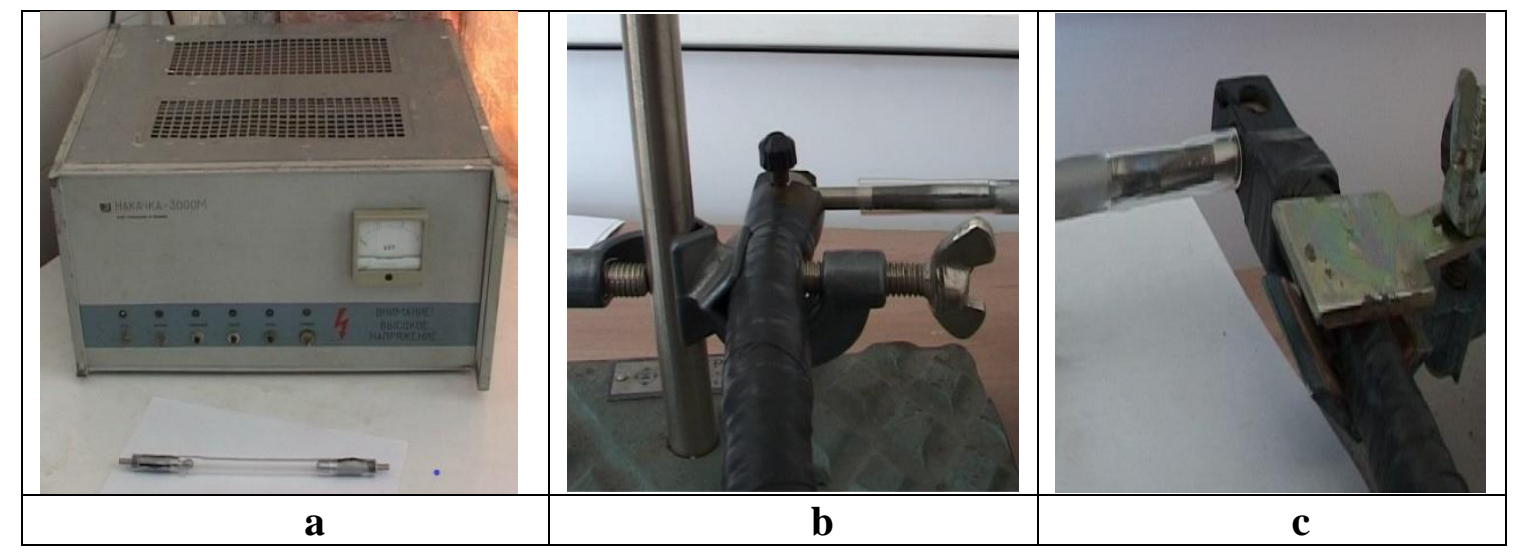

Figure 4.a. Block of capacitors and the lamps; b. left power cord; $\mathbf{c}$. right power cord

Given the dimensions of the piece subjected to surface treatment, the IPF-800 type lamp was chosen as the source of optical radiation (Figure 4a), having the following characteristics: $d=10 \mathrm{~mm}$ and $\mathrm{l}=300$ $\mathrm{mm}$; xenon filling gas; $U>700 \mathrm{~V}$ voltage at the ignition capacitors terminals; $U_{a}=2500 \mathrm{~V}$ voltage selftimer; $n=10^{6} \div 10^{7}$ impulses life span; pulses life span; light impulse perpendicular to the lamp axis $I=4.0$ $\mathrm{kd} \mathrm{s} / \mathrm{J}[9]$.

For reasons related to the uniform distribution of radiation on the work piece surface $(0.7 \% \mathrm{C}, 7 \%$ $\mathrm{Cu}$, the rest being $\mathrm{Fe}$ ), the high-power efficiency, the cylindrical shape of the lamp and the diameter, the $\Phi 11.7 \mathrm{~mm}$ inner cylindrical surface were chosen for treatment. This area was covered with soot in order to increase the absorption of the electromagnetic radiation by the piece in the surface layer [22].

The experimental fitting was performed, and the treatment operation was carried out, comprising the following steps:

- fastening the piece in the support;

- cleaning the lamp of impurities;

- placing the lamp in the piece and fixing its ends in the slots of the cables supplying power from the battery of capacitors;

- centring the lamp in the slot of the piece;

- putting into operation the block of capacitors;

- charging the block of capacitors at $\mathrm{U}=2.0 \mathrm{kV}$ and the onset of the electric discharge;

- repetition of the impulse discharge, a total number $i=3$. 
Subsequently, the piece was prepared for carrying out the metallographic analysis. For this purpose, both the flat surfaces perpendicular to the treated cylindrical surface were smoothed and polished according to STAS 4203-74 [23]. The piece was then subjected to the measurements of microstructure, which were performed with the aid of an electron beam microscope using the type of surface scanning microscopy [24].

The measuring technique is capable of achieving resolutions in the nanometre range and is based on the following principle: a probe (electronic beam) sweeps a small area of the sample, which contains information about the surface topography, the composition and other properties; a detector measures the interaction between the probe and the sample selected (emerging electrons in the case of SEM); the intensity of this interaction is encoded in the form of brightness of the image.

The SEM microscopes can produce very high-resolution images of a surface sample, showing details down to less than 1-5 nm in size. Due to the very narrow scanning band of the electron beam, the SEM microscopes have a great depth that allows obtaining three-dimensional features, useful for understanding the surface structure of the sample.

\section{Results and discussions}

The microstructure of the untreated sample after the technological process of sintering is shown in Figure 5. Undistorted equiaxial grains are noticed with diffusion zones common to the adjacent granules. The pores formed between the adjacent granules are of angular type, irregular shapes and without any preferential direction of orientation. The angular type pore has non-rounded corners, the sintering taking place in the solid state, without any liquid or viscous phase, which would have produced pores with rounded corners. The pore distribution is uniform, specific to an iron-based sintered material.

The samples were treated with metallographic reagent, so that only the morphology of the structural elements may be characterized, without showing their type. The surface treatment carried out with the gas-discharge lamp yielded the microstructures shown in Figures 6-8. The structure changes in the surface layer are due to the effects of the electric discharge in high intensity impulse (the thermal and the mechanical actions caused by the interaction of high-intensity impulses of radiation with the workpiece surface and ultra-short duration). Figures 5a and 6a present both the Spectrum 1, because they represent images of the same untreated/treated area of the piece.

Due to the second effect, the pores in the surface layer are elongated (Figure 6), without the spheroidization tendency of the ends, meaning that the temperature that allows the viscous flow of the material has not been reached. When the material flows in a viscous form, the elongated pores have a spheroidization tendency to the ends.

In Figure 7a 30-35 $\mu \mathrm{m}$ layer is observed, having the morphology different from the substrate, provided by the effects of the electromagnetic impulses of the lamp. The flow of energy emitted by the lamp in the visible spectrum creates a pressure on the surface layer, so that the pores in this layer (which is under optical influence get elongated) giving a structure similar to plastic deformation through hardening or through compaction by mechanical methods. The transfer of kinetic energy on the surface layer is achieved by the photons emitted from the optical equipment in ultra-short pulses.

In addition to the mechanical effect, in the surface layer an area of thermal influence specific to a treatment of grain grinding, along with the emergence of a network of fine cementite at the boundaries of these fine grains is observed, as depicted in Figure 8. 


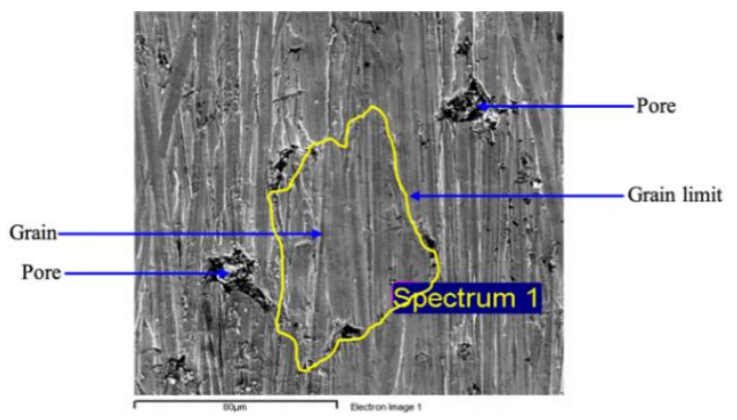

a.

Figure 5. Untreated area of the piece: $\mathbf{a}$. the structure and $\mathbf{b}$. the chemical composition

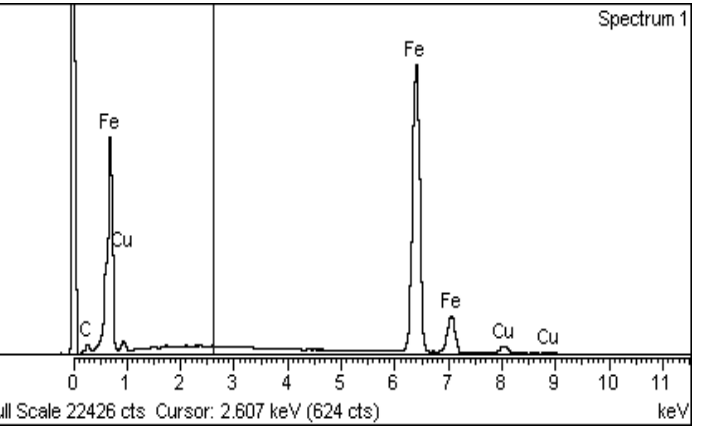

b.

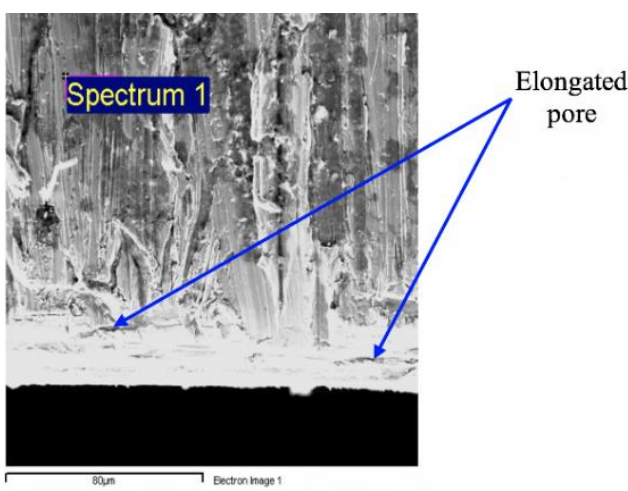

a.

Figure 6a. Structure of the piece treated on an extended portion ( $80 \mu \mathrm{m}$ scale) and $\mathbf{b}$. the chemical composition of the material of the part treated on this surface

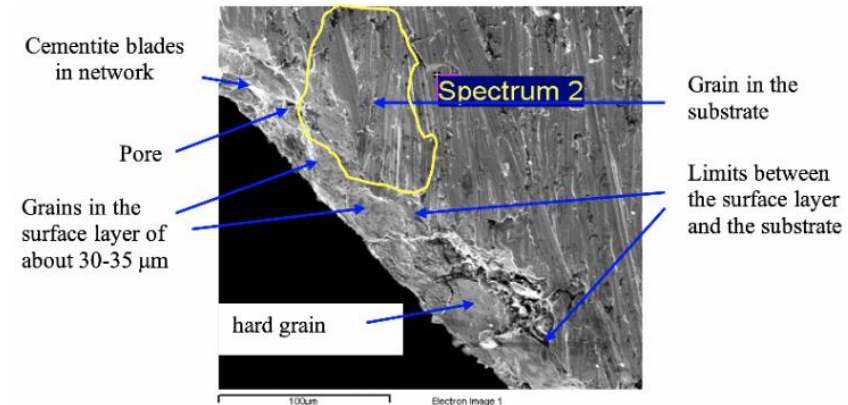

a.

Figure 7a. Structure of the piece treated at the end of the slot $(100 \mu \mathrm{m}$ scale $)$ and $\mathbf{b}$. the chemical composition of the material of the part treated on this surface

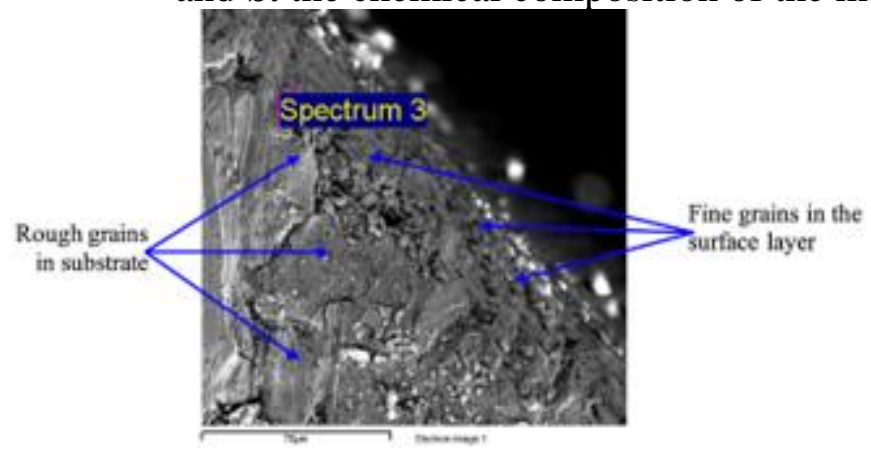

a.

Figure 8a. Structure of the piece treated at the edge of the slot $(70 \mu \mathrm{m}$ scale $)$ and b. the chemical composition of the material of the part treated on this surface

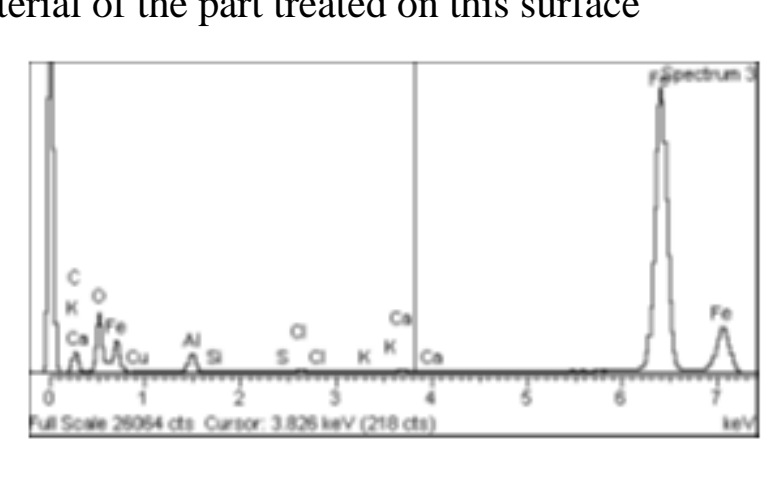

b. b.

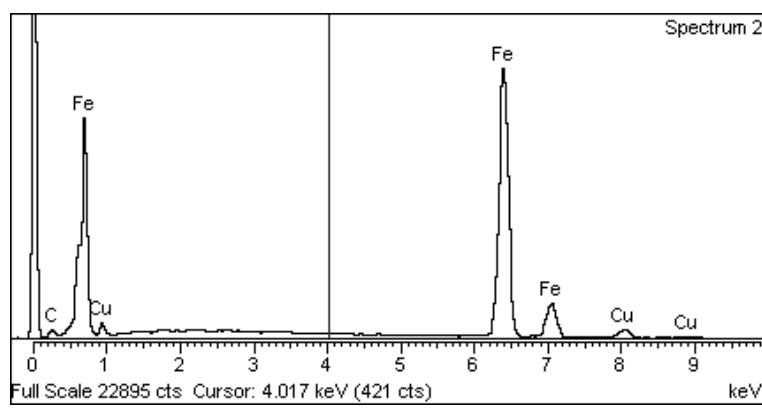

full Scale $22895 \mathrm{cts}$ Cursor: $4.017 \mathrm{keV}$ (421 cts)

b.

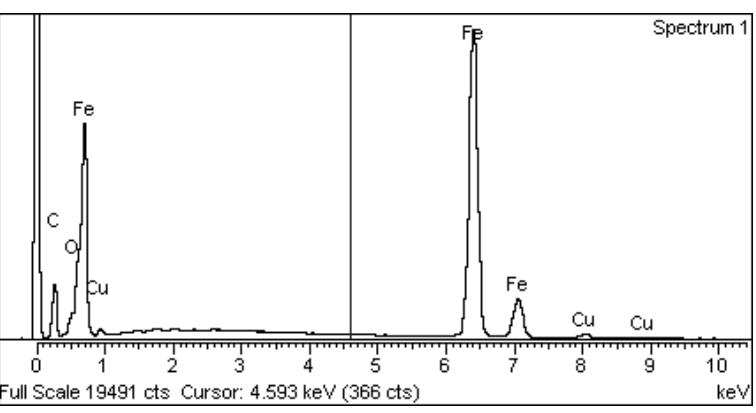


The emergence of such cementite networks is due to the precipitation of carbon under the action of the thermal effect of high-energy optical impulses, which leads to the surface hardening of the material, with beneficial effects on the resistance to attrition and to contact pressure.

The top layer consisting of very fine grains is due to the changes caused by the induction of a thermal field formed in the boundary layer up to the austenite area, followed by a rapid cooling in the air (the cooling rate is lower, but close to the heating rate), which determines the crumbling of the structure.

The physical mechanism of the changes that occur when heating with electromagnetic radiation impulses is similar to that of the laser surface treatments, taking into account the following similarities:

- the temperature of the surface layer varies extremely quickly, both in the heating and in the cooling stage;

- the transformations are based on thermal phenomena (heating, melting, solidification), the heat being respectively induced in the surface layer; as an observation, the transformations are less-based on the effect of the mechanic shock wave created by the powerful noise produced by the electric discharge in xenon, between the lamp electrodes;

- the heating and cooling speeds are approximately equal, without sample being maintained at maximum temperature.

Practically, the rate of heating and cooling significantly influences the mechanisms and kinetics of the structural changes to heating and, implicitly, the morphology of final structures and their properties after cooling. Thus, the $\gamma$ austenitic sub-structure is finished at ultra-fast heating due to the grain finishing, which has the effect of increasing the micro- and macro-hardness after tempering the martensite. Also, the austenite obtained by an ultra-fast heating is characterized by increased chemical heterogeneity in terms of the carbon content, the occurrence of a certain proportion of residual austenite not being excluded, even at average carbon content [25].

Such austenite is transformed by ultrafast cooling, usually conducted in the air without using the liquid medium, into a non-homogeneous martensite having the substructure charged with supplementary dislocations, thus with a density higher than the martensite obtained by conventional curing, known under the name of cryptocrystalline martensite $[6,26]$. The structural results change when the power source used allows to reach and surpass the critical flow at the beginning of the melting. In this situation, there occurs a surface layer melted and cooled abruptly, being possible to obtain a structure with a dendritic appearance and a lot of residual austenite, having a developed substructure and, accordingly, high hardness. In addition to the mentioned structural aspects, processes of mass transfer take place in the layer processed with partial melting, resulting changes in the chemical composition [26].

The changes of the structure have some variations in the depth of the layer affected by processing due to the thermal gradient and the cooling rate, which in turn determine variations in the proportions of phases and constituents, in their chemical composition respectively, the result being a corresponding variation of micro-hardness [27, 28].

Depending on the technology of hardening applied, as well as on the process parameters of the chosen technology, there will appear areas in the surface layer of the parts differently modified, both in structure and in depth (thickness), compared to the areas obtained after conventional superficial tempering $[28,29]$.

In this study, from the point of view of composition, the chemical changes produced in each studied area are grouped in Table 1.

Table 1. The changes produced in composition for each studied area, in the $\mathrm{C}-\mathrm{Fe}-\mathrm{Cu}$ alloy.

\begin{tabular}{|c|c|c|c|c|c|c|c|c|}
\hline \multirow{3}{*}{ Element } & \multicolumn{3}{|c|}{ Untreated piece } & \multicolumn{7}{c|}{ Treated piece } \\
\cline { 2 - 9 } & \multicolumn{3}{|c|}{ Figure 5 } & \multicolumn{3}{c|}{ Figure 6 } & \multicolumn{3}{c|}{ Figure 7 } \\
\cline { 2 - 9 } & \multicolumn{3}{|c|}{ Figure 8 } \\
\hline & Weight & Atomic & Weight & Atomic & Weight & Atomic & Weight & Atomic \\
\hline $\mathrm{C}$ & 4.50 & 18.06 & 19.15 & 50.70 & 4.01 & 16.35 & 8.30 & 25.08 \\
\hline $\mathrm{Fe}$ & 90.72 & 78.32 & 76.12 & 43.34 & 90.16 & 79.15 & 80.21 & 52.14 \\
\hline
\end{tabular}




\begin{tabular}{|c|c|c|c|c|c|c|c|c|}
\hline $\mathrm{Cu}$ & 4.78 & 3.62 & 2.31 & 1.16 & 5.83 & 4.50 & 0.68 & 0.39 \\
\hline $\mathrm{O}$ & - & - & 2.42 & 4.81 & - & - & 8.66 & 19.64 \\
\hline $\begin{array}{c}\mathrm{Al}, \mathrm{Si}, \mathrm{S}, \mathrm{Cl}, \\
\mathrm{K}, \mathrm{Ca}\end{array}$ & - & - & - & - & - & - & 2.15 & 2.75 \\
\hline
\end{tabular}

Following the analysis of the obtained results, a non-uniformity is found in the distribution of the percentage values, due precisely to the non-uniform structure of the sintered materials from metallic powders; this is explained by the fact that, in the manufacturing process, by pressing the metal granules, a different distribution and orientation of the atoms of the different elements in the powder mass takes place. On different areas of the metallic piece, following the application of the surface treatment with the pulses of optical radiation, results an increase of the carbon content of up to $19.15 \%$ in the central area (in which the flux of optical radiation was of very high intensity and evenly distributed), and lower (respectively 8.30\%) in the edge area, (where the radiant flux was lower due to losses in the surrounding atmosphere). The increase of the carbon content is due to its diffusion towards the surface of the metallic piece; the decrease of the copper percentage to the values of 2.31 and $0.68 \%$, respectively, is caused by the diffusion of the melted copper in depth.

\section{Conclusions}

The microscopic images revealed structural changes in a surface layer of about $30-35 \mu \mathrm{m}$, specific to the $\mathrm{Fe}-\mathrm{C}-\mathrm{Cu}$ alloys at a content of about $0.7 \% \mathrm{C}$ (ferrite, pearlite and cementite). The flow of energy emitted by the lamp in the visible spectrum creates a pressure on the surface layer, so that the pores in this layer that are under optical influence get elongated, giving a structure similar to plastic deformation through hardening or through compaction by mechanical methods. One can notice the fine, highly crumbled aspect of the grains in the surface layer, along with the emergence of a cementite network at the boundaries of these fine grains, which unlike the substrate must have improved roughness values. The emergence of such cementite networks in the structure of the treated pieces is due to the precipitation of carbon under the action of the thermal effect of high-energy optical impulses, which leads to the surface hardening of the material, with beneficial effects on the resistance to attrition and to contact pressure.

Acknowledgments: The authors thank Mr. Prof. Dr. Eng. Victor Nederita, from the Lucian Blaga University of Sibiu, for all the contribution brought to the identification of the world research stage in the field approached in the paper and the development in good conditions of the experimental researches.

\section{References}

1.MARIES, G.R.E., BUNGAU, C., CHIRA, D, COSTEA, T., MOSTEANU, D.E., Study on the influence of the grind percentage over the surface hardness and modulus of elasticity of parts made of acrylonitrile butadiene styrene, polyamide 6.6 and polyoxymethylene polymers, through nanoindentation, Mater. Plast., 56(1), 2019, 65-70

2.CHIRA, D., MARIES, G.R.E. BUNGAU, C., The influence of subsequent pressure of (HDPE), (PMMA), (PC+ABS) on some mechanical properties of items obtained through injection, Mater. Plast., 52(4), 2015, 572-577.

3.MARIES, G.R.E., CHIRA, D., BUNGAU, C., The influence of processing temperatures of (HDPE), (PMMA), (PC plus ABS) on some mechanical properties of items obtained through injection, Mater. Plast., 52(4), 2015, 452-456.

4.CSOKMAI, L.S.,TARCA, R.C., BUNGAU, C., HUSI, G., A Comprehensive Approach to Off-line Advanced Error Troubleshooting in Intelligent Manufacturing Systems. Int. J. Comput. Commun. Control, 10(1), 2015, 30-37.

5.OTRISAL, P., MELICHARIK, Z., SVORC, L., BUNGAU, S., VIRCA, I., BARSAN, G., MOSTEANU, D., Testing Methods of Assessment for the Chemical Resistance of Insulating Materials Against the Effect of Selected Acids, Mater. Plast., 55(4), 2018, 545-551. 
6.GINGHINA, R.E., BOJIN, D., TIGANESCU, T.V., PETREA, N., BUNGAU, S., MOSTEANU, D.E., Research on the efficiency of testing a new adsorbent material with cellulose structure for the depollution of waste water, Mater. Plast., 57(1), 2020, 306-314.

https://doi.org/10.37358/MP.20.1.5340

7.OTRISAL, P., OBSEL, V., FlORUS, S., BUNGAU C., ALEYA, L., BUNGAU, S., Protecting emergency workers and armed forces from volatile toxic compounds: applicability of reversible conductive polymer-based sensors in barrier materials, Sci. Tot. Environ., 694, 2019.

https://doi.org/10.1016/j.scitotenv.2019.133736

8.VIRCA, I., LAZAR, V., Experimental research on the influence of superficial treatsments with optical radiation impulses on the microstructure of the surfaces of sintered parts. The 16th international conference The Knowledge Based Organization, Conference Proceedings 3, Land Forces Academy Publishing House, 25-27 November 2010, Sibiu, 531-536.

9.DANNINGER, H., The Way to High Performance PM Precision Parts. Third International Conference on Powder Metallurgy RoPM 2005, I, 7-9 July 2005, Sinaia, Romania, 17-27.

10.BRAJNICOV A.E., IONOV R.N., MINAEV V.P., MITAUAR S.IA., TURCOV I.U.G., Poverhnostnaia zacalca izluceniem impulisnoi lampa, Svetotehnica, 1989, 29.

11.CRASNOV L.T., OPARIN M.I., FROLOV V.A. Termouprocinenie metaliceschih poverhnostei energhiei xenonovoi lampa, Svetotehnica, 1989, 29.

12.NEDERITA, V., CROITORU, G., O metoda termica de ridicare a proprietatilor anticorozive la otelurile utilizate in articole de beton armat (in English: A thermal method of raising the anticorrosive properties of steels used in reinforced concrete articles), Proceedings of the National Thermo-technical Conference, III, Brasov, 23-24 May 1997, 257-264.

13.FU, Y., LOREDO, A., MARTIN, B., VANNES, A.B., Laser and powder particles interaction during cladding. J. Mater. Process. Technol., 128, 2002, 106-112.

14.FU, Y., MARTIN, B., LOREDO, A., Velocity distribution of powder particles in laser cladding. Chin. J. Lasers, B11(6), 2002, 469-474.

15.LALLEMAND, G., LOREDO, A., MARTIN, B., SALLAMAND, P., VANNES, A.B., Influence of laser cladding on the surface hardness of small-diameter metallic wire substrates. Mater. Sci. Eng. A, 277(1-2); 2000, 192-197.

16.DOBRZASKI, L.A., LABISZ, K., PIEC, M., KLIMPEL, A., Mechanical properties of the surface layer of the laser alloyed 32CrMoV12-28 steel. Arch. Mater. Sci. Eng., 29(1), 2008, 57-60.

17.DOBRZASKI, L.A., POLOK, A., JONDA, E., Structure and properties of surface layers obtained by alloying of the hot work tool steels, J. Achiev. Mater. Manuf. Eng., 17, 2006, 329-332.

18.MAJUMDAR, D.J., GALUN, R., MORDIKE, B.L., MANNA, I., Effect of laser surface melting on corrosion and wear resistance of a commercial magnesium alloy. Mater. Sci. Eng. 361(1-2), 2003, 119129. https://doi.org/10.1016/S0921-5093(03)00519-7

19.MARIES, G.R.E., CHIRA, D., BUNGAU, C., COSTEA, T., MOLDOVAN, L., Determining the influence of the processing temperature by injection and of the subsequent pressure on the surface's hardness and indentation modulus of the products made of HDPE, PMMA, PC+ABS through nanoindentation - G-Series basic hardness modulus at a depth method. Mater. Plast., 54(2), 2017, 214 220.

20.FECKOVA, Z. Surface Treatment of Powder Material by Metal Coatings - Study of Corrosion Properties, J. Metals, Materials Minerals, 17(1), 2007, 41-46.

21.***STAS 10677-84, Oteluri pentru calire superficiala. Marci si conditii tehnice de calitate. (in English: Surface hardening steels. Brands and quality technical conditions) https://asr.ro/documents/ standardizare/42/042.02.2017-09-30-Oteluri-produse.pdf (accesed 11 September 2019)

22.DOMSA, S., ORBAN, R., Obtinerea pieselor prin metalurgia pulberilor, în Materiale inginereşti şi tehnologii competitive. Ed. Casa Cartii de Stiinta, Cluj-Napoca, 2001, 193-200.

23.***STAS 4203-74, Testing of metals, ICS: 77.040.01. https://www.iso.org/ics/77.040/x/ (accesed 10 September 2019) 
24.JOY, D.C., Scanning electron microscopy for material characterization, Curr. Opin. Solid State Mater. Sci., 2(4)., 1997, 465-468.

25.MEISER, J., URBASSEK, H.M., Influence of the Crystal Surface on the Austenitic and Martensitic Phase Transition in Pure Iron, Crystals, 8, 2018, 469.

26.MEISER, J., URBASSEK, H.M., Ferrite-to-Austenite and Austenite-to-Martensite Phase Transformations in the Vicinity of a Cementite Particle: A Molecular Dynamics Approach. Metals, 8, $2018,837$.

27.KIM, R., BAE, C., KIM, J., Initial Deformation Behaviors in Lean Duplex Stainless Steel, Metals, 10, 2020, 936.

28.MYROLD, B., JENSRUD, O., SNILSBERG, K.E., The Influence of Quench Interruption and Direct Artificial Aging on the Hardening Response in AA6082 during Hot Deformation and In-Die Quenching, Metals, 10, 2020, 935.

29.LU, D., ZHANG, K., HU, G., LAN, Y., CHANG, Y., Investigation of Yield Surfaces Evolution for Polycrystalline Aluminum after Pre-Cyclic Loading by Experiment and Crystal Plasticity Simulation. Materials, 13, 2020, 3069.

$\overline{\text { Manuscript received: } 17.07 .2020}$ 